\title{
Determination of residual stress in bonded wood components
}

\section{Journal Article}

\section{Author(s):}

Scheffler, Michael; Weber, Tony; Niemz, Peter; Hardtke, Hans-Jürgen

Publication date:

2007

Permanent link:

https://doi.org/10.3929/ethz-b-000005138

Rights / license:

In Copyright - Non-Commercial Use Permitted

Originally published in:

Holzforschung 61(3), https://doi.org/10.1515/HF.2007.065 


\section{Determination of residual stress in bonded wood components}

\author{
Michael Scheffler,*, Tony Weber $^{3}$, Peter Niemz ${ }^{2}$ \\ and Hans-Jürgen Hardtke ${ }^{1}$ \\ 1 Institut für Festkörpermechanik, Lehrstuhl \\ Maschinendynamik und Schwingungslehre, \\ TU Dresden, Dresden, Germany \\ ${ }^{2}$ Institut für Baustoffe, Wood Physics, ETH Zürich, \\ Zürich, Switzerland \\ ${ }^{3}$ Institut für Leichtbau, TU Dresden, Dresden, Germany \\ *Corresponding author. \\ TU Dresden Institut für Festkörpermechanik, Lehrstuhl \\ Maschinendynamik und Schwingungslehre, TU Dresden, \\ Helmholzstrasse 10, D-01069 Dresden, Germany \\ Phone: +49-351-46337974 \\ E-mail: michael.scheffler@tu-dresden.de
}

\begin{abstract}
Climate tests on double-layered samples were performed to detect deformation and induced stress concentrations. The paper is divided into two parts. The first presents experimental results for double-layered specimens. These specimens consisted of two wooden layers (each conditioned at a different climate before bonding) that were bonded using two different adhesives. The displacement field of the specimens was measured by means of digital fringe projection. The second part presents finite element results for two model stages using coupled thermal-mechanical analysis. For the first simple model, both orthotropic properties and the grain orientations were taken into account to investigate the behavior of the layers in principle. The results were compared to those for the experimental set-up. The improved second-stage model considers the adhesive layer between the wooden layers. The experimental and computational results of the improved simulation model are in good agreement. In the future, if inelastic material behavior is considered in a competitively superior manner, even better simulation results can be expected.
\end{abstract}

Keywords: deformation; finite element analysis (FEA); fringe pattern method; glue line; longitudinal tensile shear; strain.

\section{Introduction}

Mechanically stable glued timber such as glued-laminated timber (glulam), plywood, laminated veneer lumber (LVL) and parallel strand lumber (PSL) are widely used for wood constructions. In comparison to concrete and steel, they have a low payload and their production requires less energy. They can be produced in many different geometric shapes. Endless board-lamellas of glu- lam, for example, allow nearly unrestricted design space (Wenzel et al. 2005).

A better understanding of the mechanisms of gluing formation in glulam is necessary to improve its bending strength and avoid warpage. The mechanics of glued joints generally deserve closer attention. Mechanical stresses in the glued joint may cause problems; they may induce cracks in the entire glulam body, starting from the adhesive joint. In the present paper, the formation of warpage was detected by measuring the digital fringe pattern and compared to results of a finite element simulation model.

\section{Materials and methods}

\section{Sample preparation}

The samples used were made from Norway spruce (Picea abies Karst.) with dimensions of $150 \mathrm{~mm} \times 150 \mathrm{~mm} \times 5 \mathrm{~mm}$ (width $\times$ length $\times$ thickness). The raw material was a defect-free board with a straight-line grain with different radial orientations. One section of the sample was bonded using polyurethane solution adhesive (Purbond HB 110, PURBOND), while the other part was glued using UF resin (Placol 4500, Geistlich). UF resin adhesive joints are considered to be brittle, in contrast to polyurethane joints, which are more ductile. The investigation was carried out at a constant temperature. All other environmental conditions during gluing were also almost constant. The combinations of variations in grain and climate conditions between the layers are shown in Table 1; each experiment was performed on four specimens (A, B, C and D). The nomenclature used is as follows. Specimen 35-85-PUR-B indicates climate for the lower layer (35\% relative humidity, $\mathrm{RH})$, climate for the upper layer ( $85 \% \mathrm{RH})$, adhesive (PUR) and specimen number (B). The specimens were stored in a climate chamber at $20^{\circ} \mathrm{C}$ and $35 \%$ $\mathrm{RH}$ until an equilibrium moisture content (MC) of $8 \%$ was reached. The layers were then conditioned at different $\mathrm{RH}$ values (Table 1) and glued. All samples were prepared at a spreading quantity of $200 \mathrm{~g} \mathrm{~m}^{-2}$ wood and a pressure of $0.25 \mathrm{~N} \mathrm{~mm}^{-2}$ at $20^{\circ} \mathrm{C}$. These conditions were held constant for Purbond and UF resin samples for a period of 3 and $4 \mathrm{~h}$, respectively.

After reconditioning, the digital fringe pattern was measured at TU Dresden to observe the deformation of each specimen. This method, as explained below, was used in preference to electronic speckle pattern interferometry (Gindl et al. 2005; Müller et al. 2005).

\section{Basic principles of digital fringe pattern projection}

This optical method is generally applied for measuring 3D data and comparing data obtained to those predicted using computer-aided design (CAD) software. Fringe patterns are projected onto the object's surface using white light and then viewed from another direction. The projector codes the sample surface with a combination of grayscale fringe patterns and phase information. In the ATOS (GOM, Germany) system used, patterns are recorded by two cameras to achieve better-quality measurement 
Table 1 Specimen and layer scheme for climate conditions, grain and adhesive.

\begin{tabular}{|c|c|c|c|c|}
\hline \multirow{2}{*}{$\begin{array}{l}\text { Lower } \\
\text { layer }\end{array}$} & \multicolumn{4}{|c|}{ Upper layer } \\
\hline & $35 \% \mathrm{RH}$ & $43 \% \mathrm{RH}$ & $65 \% \mathrm{RH}$ & $85 \% \mathrm{RH}$ \\
\hline $35 \%$ RH & UF $\perp$ & - & - & - \\
\hline $43 \% \mathrm{RH}$ & $\begin{array}{l}\text { UF } \perp \\
\text { UF \| } \\
\text { PU \| }\end{array}$ & $\mathrm{UF} \perp$ & - & - \\
\hline $65 \% \mathrm{RH}$ & $\begin{array}{l}\text { UF } \perp \\
\text { UF \| } \\
\text { PU \|I }\end{array}$ & $\begin{array}{l}\text { UF } \perp \\
\text { UF \| } \\
\text { PU \|I }\end{array}$ & $\mathrm{UF} \perp$ & - \\
\hline $85 \% \mathrm{RH}$ & $\begin{array}{l}\text { UF } \perp \\
\text { UF \| } \\
\text { PU \|I }\end{array}$ & $\begin{array}{l}\text { UF } \perp \\
\text { UF \| } \\
\text { PU \|I }\end{array}$ & $\begin{array}{l}\text { UF } \perp \\
\text { UF \| } \\
\text { PU \|I }\end{array}$ & $\mathrm{UF} \perp$ \\
\hline
\end{tabular}

UF, UF resin adhesive; PU, polyurethane; $\perp$, layers perpendicular; |l, layers parallel.

results. Figure 1 shows the experimental set-up for the fringe pattern system.

When the fringes are viewed at an angle $\zeta$ relative to the projection direction, the spacing $d$ of the lines perpendicular to the viewing direction will be:

$d=\frac{p}{\cos \zeta}$.

The contour interval $C$ (height between adjacent contour lines in the viewing direction) is determined by the line or fringe spacing projected onto the surface and the angle between the projection and viewing directions:

$C=\frac{p}{\sin \zeta}=\frac{d}{\tan \zeta}$.

Each measurement is automatically transformed into a common object coordinate system by ATOS. Deviations from the reference model may be calculated. The complete 3D data set and the comparison results may be exported into standard formats for further processing, such as for calculation of the deformation. It is possible to calculate the surface coordinates for up to four million measurement points in a few seconds.

In this investigation, cross-laminates were used as reference models having the same geometry as the test specimen without any deflections or warpage. Figure 2 shows an example of scattered test data for the reference model and the related reference plane.

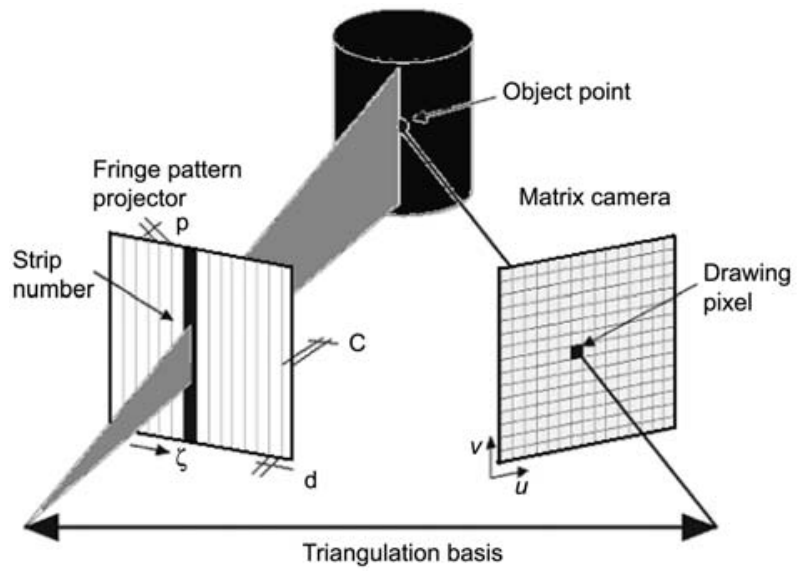

Figure 1 Schematic drawing of the optical system for measurement of fringe patterns according to Wiora (2001).

An alternative method for measuring the overall deflection of a test specimen is to determine the deflection radius (Figure 3 ). The advantage is that only a single scalar is needed for comparing different specimens. In addition, this single parameter is easier to detect and measuring faults are reduced.

\section{Finite element analysis}

In the finite element code ANSYS, moisture-induced stresses cannot be directly calculated. Thus, a moisture-heat analogy was applied, as presented in the following differential equations. The time-dependent moisture field $u$ without inner moisture/temperature generation is described by:

$\frac{\partial u}{\partial t}=\nabla \cdot(D \nabla u)$

and the temperature field $T$ can be described as:

$\frac{\partial T}{\partial t}=\frac{1}{\rho_{\mathrm{dry}} \cdot C_{\mathrm{wet}}} \nabla \cdot(\lambda \nabla T)$

where $\rho_{\mathrm{dry}}$ is the density of dried material and $c_{\text {wet }}$ is the specific heat of moist material.

The finite elements used were 3D elements with thermalstructural field capability, with limited coupling between the fields. This element (ANSYS Element SOLID5) has eight nodes with up to six degrees of freedom at each node. Displacements

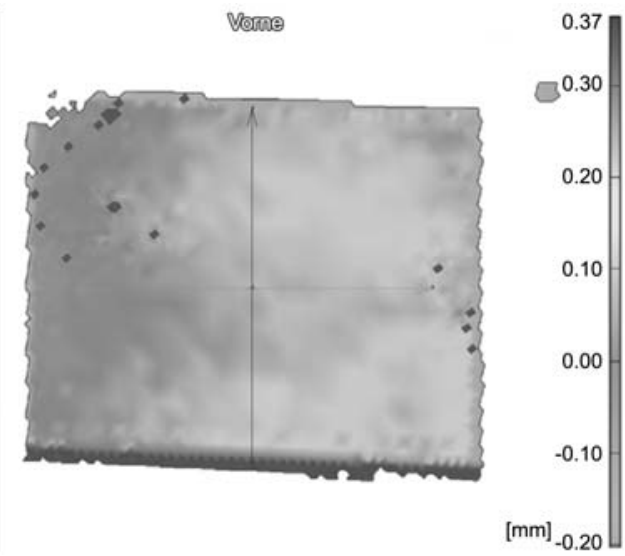

Figure 2 Scatter diagram of the best-fit reference model (left) and the reference plane generated for fringe pattern measurement (right). 

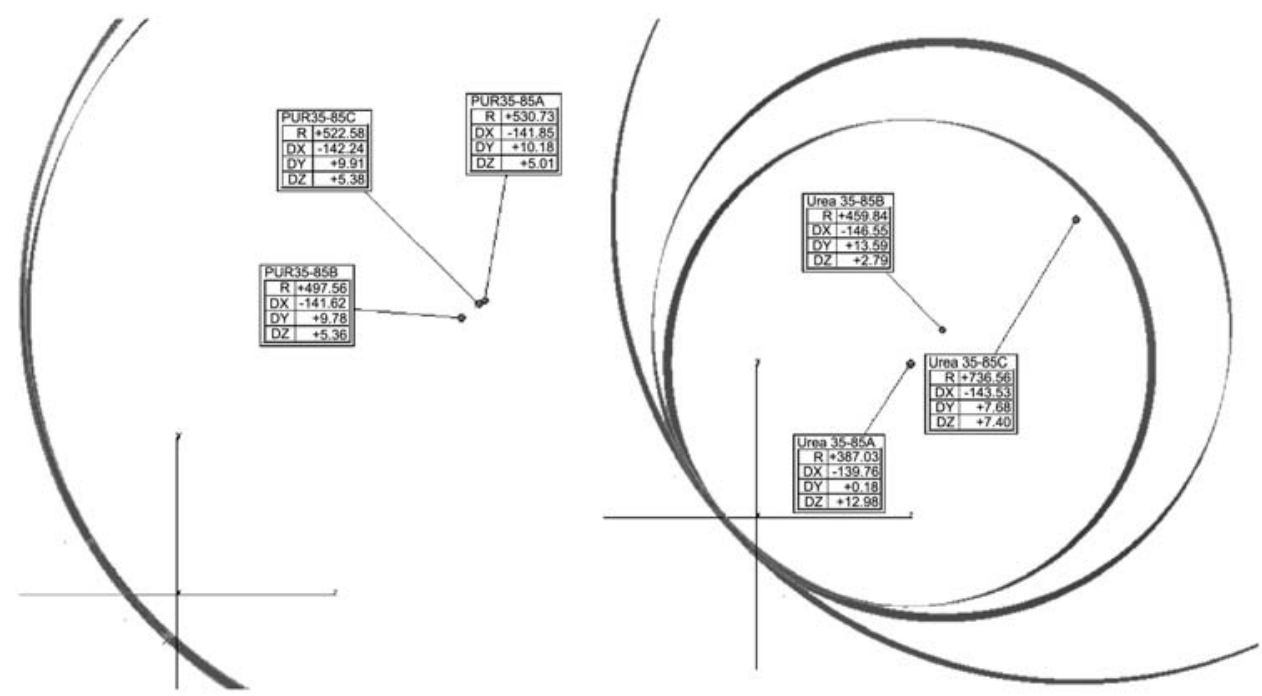

Figure 3 Deflection radius, which is an easier parameter to detect, measured for analogous specimens: 35-85-PUR (left) and $35-85$-urea (right). Note the spreading of UF resin samples.

are generated for a stress-free support, as demonstrated in Figure 4 , and moisture stresses are calculated from moisture difference $\Delta u$ :

$\Delta u=u-u_{\text {ref }}$

where $u_{\text {ref }}$ denotes the initial moisture. Figure 4 illustrates the kinematic boundary conditions, as well as the initial moisture field.

Nodal local coordinate systems are rotated into the global cylindrical system to obtain local orthotropic properties according to Table 1. Basic relations for the mechanical material parameters, such as the modulus of elasticity, can be found in Niemz (1993). Usually, constitutive equations for wooden materials under changing climatic conditions must be described in terms of:

- Viscoelasticity, describing the time-dependent deformations; and

- A mechanosorptive material model (coupling of mechanic and moisture effects).

However, the lack of material parameters and the software available led to a simplified material model in which correction factors for elastic deformations had to be used. Nevertheless, one advantage of this approach is a significant reduction in calculation time in comparison to a complete simulation model with viscoelastic and mechanosorptive effects.

Therefore, elastic layers were assumed. The following equation allows for consideration of the time-dependent behavior, with the effective parameters $\varphi_{\text {eff }}$ calculated from the initial values at standard climatic conditions $\left(20^{\circ} \mathrm{C}, 65 \% \mathrm{RH}, \varphi_{n(20 / 65)}\right)$ :

$\varphi_{\text {eff }}=k_{\mathrm{L}} \cdot k_{\mathrm{C}} \cdot \varphi_{n(20 / 65)}$,

where $k_{\mathrm{L}}$ is the load correction factor and $k_{\mathrm{C}}$ the correction factor for the climate at a particular moisture. The reference parameters $\varphi_{n(20 / 65)}$ for material direction parallel $(0.1-0.3)$ and perpendicular to the grain $(0.8-1.6)$ are different. The load correction factor $k_{\mathrm{L}}$ is estimated at $10 \%$ of tensile strength, and the values range from 1.1 to 1.3. The $k_{\mathrm{c}}$ factor is between 1.8 and 2.0 for a constant $\mathrm{RH}$ of $80 \%$ and between 1.4 and 1.8 for an atmosphere with changing humidity. A conservative estimation of $\varphi_{\text {eff }}$ yields:

$\varphi_{\text {eff_parallel }}=1.1 \cdot 1.4 \cdot 0.3=0.462$
$\varphi_{\text {eff_perpen }}=1.1 \cdot 1.4 \cdot 0.8=1.232$.

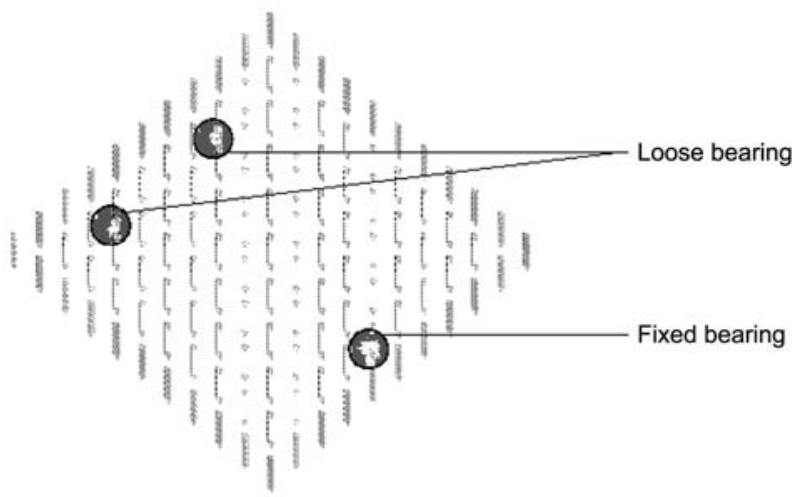

Figure 4 Nodes of the finite element model with boundary conditions: $\bigcirc$, nodal displacements; I, nodal temperatures equivalent to moisture.

Table 2 Effective Young's modulus $(E)$ of bonded wood components compared to their initial values.

\begin{tabular}{lcc}
\hline Property & Initial value & Effective value \\
\hline$E_{\mathrm{L}}(\mathrm{MPa})$ & 13000 & 8900 \\
$E_{\mathrm{R}}(\mathrm{MPa})$ & 818 & 400 \\
$E_{\mathrm{T}}(\mathrm{MPa})$ & 420 & 200 \\
\hline
\end{tabular}

Subscripts indicate directions: $L$, longitudinal; $R$, radial; and $T$, tangential.

Table 3 Elastic parameters of adhesives (Konnerth et al. 2006)

\begin{tabular}{lccc}
\hline Adhesive & $E$ & $G$ & $\nu$ \\
& $(\mathrm{MPa})$ & $(\mathrm{MPa})$ & \\
\hline MUF & $6300 \pm 920$ & 2400 & $0.34 \pm 0.073$ \\
$1 \mathrm{~K} \mathrm{PU}$ & $470 \pm 89$ & 180 & $0.30 \pm 0.051$ \\
\hline
\end{tabular}

$E$, Young's modulus; $G$, shear modulus; $\nu$, Poisson's ratio; MUF, melamine-urea-formaldehyde; PU, polyurethane.

Table 2 shows the effective elastic parameters; the shear moduli remain unchanged. The elastic properties for the adhesives were those listed in Table 3 owing to the lack of a better data basis. This relatively simple model results in deformations and mechanical stresses. A detailed discussion of the applica- 


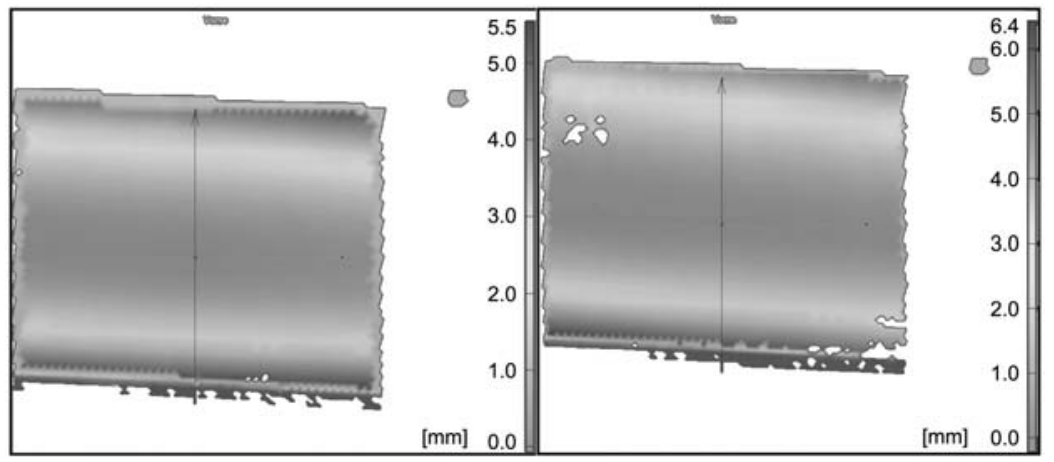

Figure 5 Deflection measured for 35-85-PUR-B (left) and 35-85-urea-B (right): the contour bar shows the deflection in $\mathrm{mm}$ (left maximum, $5.5 \mathrm{~mm}$; right maximum, $6.4 \mathrm{~mm}$ ).

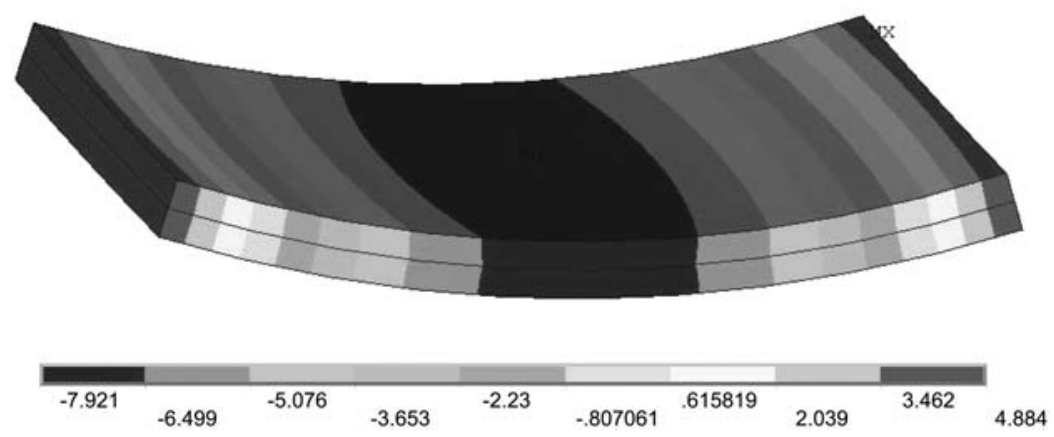

Figure 6 Finite element simulation model $(150 \mathrm{~mm} \times 150 \mathrm{~mm} \times 5 \mathrm{~mm})$ sum of displacements: the contour bar shows the deflection in $\mathrm{mm}$.

tion of finite elements for joints can be found in Wernersson (1994).

\section{Results and discussion}

\section{Optical measurements}

The results are presented and compared based on a selected set of specimens; for a full survey of results, see Weber (2005). The influence of the two different adhesives is evident in Figure 5, which compares deflection measured for a PUR-bonded sample (35-85-PUR-B) and a UF resin sample (35-85-urea-B).

The cylindrical warpage of the samples is clearly evident. Maximum deflection is $5.5 \mathrm{~mm}$ for 35-85-PUR-B and $6.4 \mathrm{~mm}$ for $35-85$-urea-B, as expected. The variability observed is much higher for the UF bonded samples than for PUR samples, as visible in Figure 3, which shows the deflection radii of three samples in each analogous case.

Compared to PUR-bonded samples (max. $5.5 \mathrm{~mm}$ ), the UF resin-bonded samples (max. $6.4 \mathrm{~mm}$ ) revealed $10 \%$ greater deflection and a higher mean distribution of deflection values. This effect may be induced by the slightly higher modulus of elasticity.

\section{Finite element analysis: basic simulation model}

A first-stage simulation model without adhesives and with the initial elastic parameters was established to demonstrate the main principles of the mechanical behavior of the different layers and the necessity for effective elastic parameters according to Eqs. (6) and (7). Figure 6 illustrates a typical deformation plot that is in agreement, at least in principle, with the experimental results. Nevertheless, it is possible to compute accurate deflections, although the stresses are overestimated. Table 4 permits a comparison between the maximum measurements and the calculated deflections and mechanical stresses.

\section{Comparison of measured and simulated results for the improved simulation model}

Calculated and simulated results are in relatively good agreement (Figure 7). PUR-bonded specimens (parallel) and UF resin-bonded specimens (cross) result in analogous findings. Table 5 exhibits the mechanical stresses computed for the simplified material model according to Eqs. (6) and (7). The influence of the different adhesives can be observed in Table 6 . The effects of the different grain orientations are listed in Table 7.

The maximum difference between the measured and computed results is $8 \%$ (see also Tables 6 and 7). This can be explained in terms of differences in material para-

Table 4 Comparison of parallel laminates according to Eq. (7) (laminate 35-85-A, UF resin adhesive).

\begin{tabular}{|c|c|c|c|c|c|}
\hline \multirow{3}{*}{$\begin{array}{l}\text { Effective } \\
\text { parameter }\end{array}$} & \multicolumn{4}{|c|}{ Stress (MPa) } & \multirow{3}{*}{$\begin{array}{l}\text { Maximum } \\
\text { deflection } \\
(\mathrm{mm})\end{array}$} \\
\hline & \multicolumn{2}{|c|}{ Longitudinal } & \multicolumn{2}{|c|}{ Radial } & \\
\hline & Min. & Max. & Min. & Max. & \\
\hline$\varphi_{n(20 / 50)}$ & -10.5 & 10.2 & -5.5 & 4.9 & 6.4 \\
\hline$\varphi_{\text {eff perpen }}$ & -6.7 & 6.6 & -2.9 & 2.6 & 6.4 \\
\hline
\end{tabular}




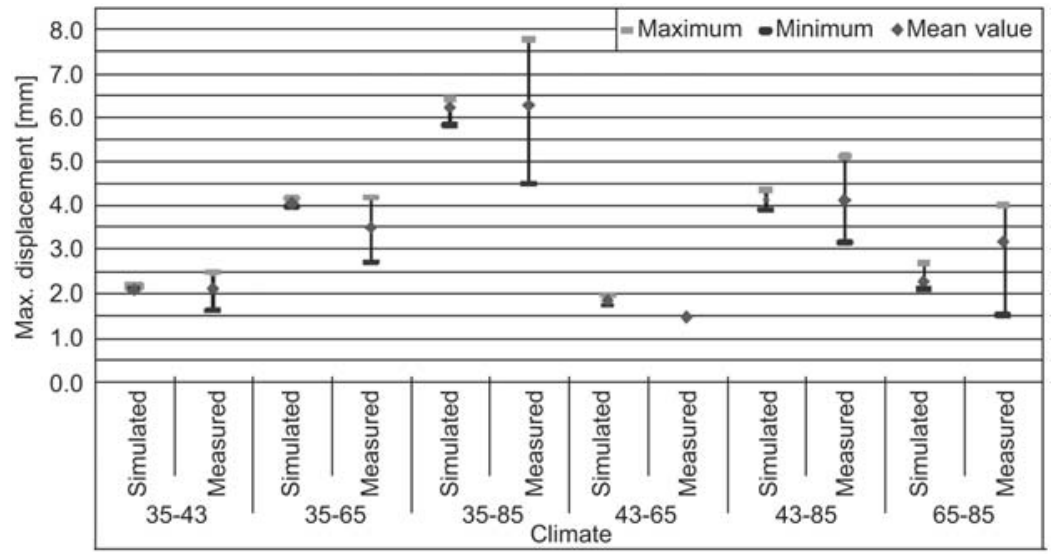

Figure 7 Comparison of displacements of UF resin bonded specimens (parallel).

Table 5 Comparison of cross-laminates according to Eq. (7) (laminate 85-85-A, UF resin adhesive).

\begin{tabular}{|c|c|c|c|c|c|}
\hline \multirow{3}{*}{$\begin{array}{l}\text { Effective } \\
\text { parameter }\end{array}$} & \multicolumn{4}{|c|}{ Stress (MPa) } & \multirow{3}{*}{$\begin{array}{l}\text { Maximum } \\
\text { deflection } \\
(\mathrm{mm})\end{array}$} \\
\hline & \multicolumn{2}{|c|}{ Normal } & \multicolumn{2}{|c|}{ Radial } & \\
\hline & Min. & Max. & Min. & Max. & \\
\hline$\varphi_{n(20 / 50)}$ & -29.9 & 21.4 & -27.6 & 20.6 & 4.9 \\
\hline$\varphi_{\text {eff perpen }}$ & -16.9 & 12.3 & -16.5 & 12.2 & 4.2 \\
\hline
\end{tabular}

meters, such as adhesives, the width of the annual rings (and their density), small differences in the grain angle in the radial-tangential direction, and measurement errors.

Finally, by formation of a bond line, adhesive penetration into the wood can be observed, which may change the mechanical properties of the wood cells to a large degree. Thus, a simple model - as employed here - cannot describe exactly the real stress and strain conditions in a bond line. Therefore, direct measurement of strain distributions is necessary to optimize the simulation model.

Regardless of deviations in strain distributions, the finite element results are quite comparable with results

Table 6 Influence of the different adhesives used: maximal deflection of analogous specimens (35-85-urea-B and 35-85PUR-B).

\begin{tabular}{lcc}
\hline Adhesive & \multicolumn{2}{c}{ Deflection (mm) } \\
\cline { 2 - 3 } & Measured & Computed \\
\hline UF & 6.8 & 6.5 \\
PU & 5.6 & 6.1 \\
\hline
\end{tabular}

UF, UF resin adhesive; PU, polyurethane. for the digital fringe pattern projection in terms of the overall strain distribution. Accordingly, the potential of this method is high and it can contribute to a better understanding of the mechanical interactions in adhesively bonded wood.

\section{Summary and conclusions}

The influence of different adhesives, grain orientations, and climate conditions for glulam materials made from Piecea abies has been investigated. Test results for real specimens were compared with results obtained from simulation models.

Comparison of PUR and UF resin adhesives revealed greater deflections for UF resin-bonded specimens, which are due to the differences in elastic parameters (Table 3). Gindl and Müller (2006) and Sretenovic et al. (2005) reported similar results.

The improved model based on static load factors and the adhesive layer showed good agreement with experiments in terms of the variance of physical properties of native wood and adhesive materials. The deflection deviation was nearly $8 \%$ lower than the variance in material properties. This minimal model is a first approach that provides a good estimation of the mechanical behavior and can be further developed. It is possible to compute mechanical stresses in the bond line, whereas distortion measurements are needed to obtain real stresses for model improvements. Obviously, it is doubtful whether a simple correction according to Table 2 is justified. For better results, a simulation model must include an improved material model consisting of orthotropic vis-

Table 7 Influence of annual rings (urea-35-85-A) on deflection for different variants of deviation to the shoot axis.

\begin{tabular}{|c|c|c|c|c|c|c|}
\hline \multicolumn{7}{|c|}{$\begin{array}{l}\text { Image of a } \\
\text { representative } \\
\text { sample }\end{array}$} \\
\hline Sample & 1 & 2 & 1 & 2 & 1 & 2 \\
\hline$\Delta x(\mathrm{~mm})$ & -200 & 50 & -200 & -250 & -200 & 100 \\
\hline$\Delta y(\mathrm{~mm})$ & -30 & -10 & -60 & 70 & -2.5 & -2.5 \\
\hline$w_{\text {comp }}(\mathrm{mm})$ & 6.4 & & 7.8 & & 5.9 & \\
\hline$W_{\text {meas }}(\mathrm{mm})$ & & & 7.7 & & & \\
\hline
\end{tabular}

$\Delta x$, horizontal deviation to shoot axis; $\Delta y$, vertical deviation to shoot axis; $w_{\text {comp }}$, maximal computed deflection; and $w_{\text {meas }}$, maximal measured deflection. 
coelasticity and mechanosorptive behavior, in addition to pure elastic stress-deformation behavior. With these additional effects, a better approximation of experimental data should be possible. However, such a sophisticated model needs much more experimental and computational effort. Moreover, a superior finite-element code with advanced material description options is required, as proposed by Serrano (1997) and Serrano and Enquist (2005). MARC, which is a standard non-linear finite element code with superior non-linear material features, is a good candidate for such simulations (Hardtke et al. 1997; Scheffler 2001).

\section{References}

Gindl, W., Müller, U. (2006) Shear strain distribution in PRF and PUR bonded 3-ply wood sheets by means of electronic laser speckle interferometry. Wood Sci. Technol. 40:351-357.

Gindl, W., Sretenovic, A., Vincenti, A., Müller, U. (2005) Direct measurement of strain distribution along a wood bond line Part II: Effects of adhesive penetration on strain distribution. Holzforschung 59:307-310.

Hardtke, H.-J., Militzer, K.-E., Fischer, R., Hufenbach, W. (1997) Entwicklung und Identifikation eines kontinuumsmechanischen Modells für die numerische Simulation der Trocknung von Schnittholz. Technical Report DFG-Nr. Ha 2075/3-2. TU Dresden, Germany.

Konnerth, J., Gindl. W., Müller, U. (2006) Elastic properties of adhesive polymers. Part I: Polymer films by means of electronic speckle pattern interferometry. J. Appl. Polym. Sci. 103:3936-3939.
Müller, U., Sretenovic, A., Vindenti, A., Gindl, W. (2005) Direct measurements of strain distribution along a wood bond line - Part I: Shear strain concentration in a lap joint specimen by means of electronic speckle pattern interferometry. Holzforschung 59:300-306.

Niemz, P. Physik des Holzes und der Holzwerkstoffe. LeinfeldenEchterdingen, DRW, 1993

Scheffler, M. (2001) Bruchmechanische Untersuchungen zur Trockenrissbildung an Laubholz. Ph.D. thesis, TU Dresden, Germany (published by GCA Herdecke in 2002).

Serrano, E. (1997) Finger joints for laminated beams. Experimental and numerical studies of mechanical behaviour. Report TVSM-3021. Lund University, Sweden.

Serrano, E., Enquist, B. (2005) Contact-free measurement and non-linear finite element analyses of strain distribution along wood adhesive bonds. Holzforschung 59:641-646.

Sretenovic, A., Müller,U., Gindl, W. (2005) Comparison of the inplane shear strength of OSB and plywood using five point bending and EN 789 steel plate test method. Holz Roh Werkst. 63:160-164.

Weber, T. (2005) [Computational and experimental investigation of strain in glued-laminated timber]. Bachelor thesis, TU Dresden, Germany (in German).

Wenzel, R., Schmidt, J., Resch, E., Kaliske, M. (2005) Zum Tragverhalten von BSH-Trägern unter Berücksichtigung streuender Materialparameter. LACER 10:145-160.

Wernersson, H. (1994) Fracture characterization of wood adhesives joints. Report TVSM-1006. Lund University, Sweden.

Wiora, G. (2001) Optical 3D-metrology: Precise shape measurement with an extended fringe projection method. Ph.D. thesis, Universität Heidelberg, Germany.

Received September 20, 2006. Accepted March 3, 2007. 